\title{
Earth-science centre targets core questions
}

\section{David Cyranoski, Tokyo}

Earth scientists are hoping that a new, purpose-built institute that has opened outside Tokyo may help them to gain insight into the workings of the planet's interior.

The researchers are confident that the Institute for Frontier Research on Earth Evolution (IFREE) will provide the impetus for stronger multidisciplinary research. With around 100 research staff and an annual budget of $¥ 1.5$ billion (US $\$ 12$ million), they say, the institute should have the resources to make substantial progress in understanding how the planet evolved.

"The institute is an attempt to overcome the walls that separate researchers in Japanese universities," says Ikuo Kushiro, IFREE's first director, a former professor of geology at the University of Tokyo.

Earlier this month, 70 researchers at the institute, which is part of the Japan Marine Science and Technology Center (JAMSTEC) in Yokosuka, held a workshop to hammer out its early research priorities.

IFREE will initially concentrate on two sets of problems: the interaction over time between the Earth's interior and the movement of tectonic plates on its surface, or crust; and the influence of the interior on the formation and deformation of the crust at subduction zones, which are areas where tectonic plates overlap.

In addressing the first problem, the researchers agreed to focus their investigations on particular periods of change during the past 200 million years. These include the plate reorganization of the Eocene epoch

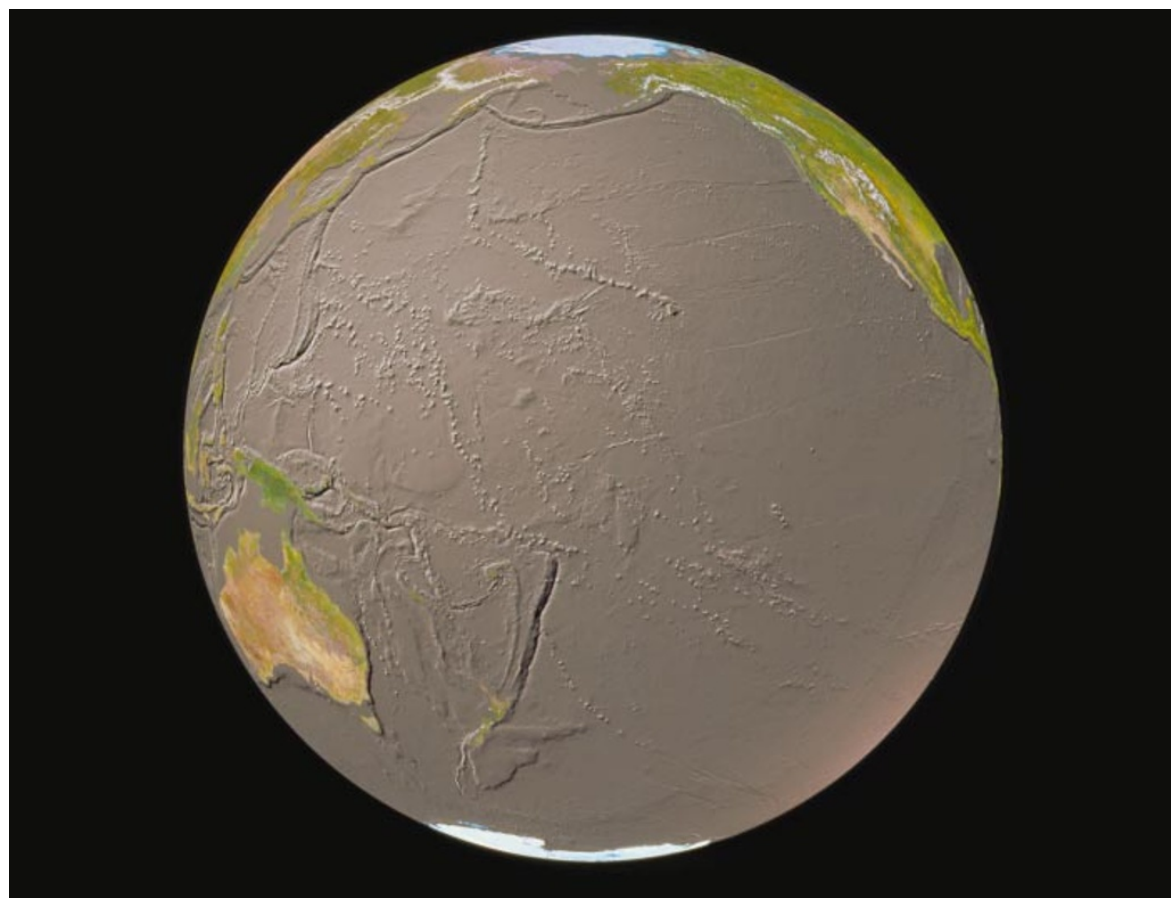

Under scrutiny: the Japanese centre will focus on the underlying causes of geological features such as the trenches and volcanoes shown in this augmented satellite image.

(40-50 million years ago), superwarming during the Cretaceous period (around 100 million years ago), and the break-up of the Pangea supercontinent (around 180 million years ago).

With regard to the second issue, the researchers will concentrate on the IzuBonin-Mariana subduction zone, which stretches from Japan to Guam, and specifi-

\section{Canada unveils science strategy}

David Spurgeon, Montreal

Canada must double its population of trained researchers, its number of grant awards for graduate students, and its federal investment in research and development, says an innovation strategy document published by the government last week.

The document, which was released by Allan Rock, the industry minister, also proposes moves to attract more students from abroad. Admitting that Canadians' quality of life is declining relative to the United States, Rock warns that it will fall even further unless Canada "stems the outflow of talent and capital".

The paper says that Canada should give priority to supporting the direct costs of university research, implement an award for industrial innovation, and, through the Canadian Academies of Science, build stronger national scientific bodies.
The strategy paper was welcomed by industrial and scientific organizations, although critics say that it lacks either hard commitments to spending money or specific details of how its objectives will be met.

It "shows tremendous foresight", says Mike Lazaridis, president of Research In Motion, who gave Can $\$ 100$ million (US\$63 million) to found the Perimeter Institute for Theoretical Physics in Waterloo, Ontario (see Nature 414, 391; 2001).

Nancy Hughes Anthony, president of the Canadian Chamber of Commerce, says the business community welcomes the strategy, particularly the policies for making the economy more competitive. But "innovation must be driven by the private sector", she says.

A series of meetings will now be held to discuss the strategy, culminating in a plan to implement it over a 10 -year period. t www.innovationstrategy.gc.ca cally on the role of water there. Oceanic water enters the mantle - the region between the Earth's crust and core - at the subduction zones. "The inserted water plays an essential role in earthquakes, crustal deformation and mantle convection, as well as in volcanic eruptions and crustal formation," says Yoshio Fukao, a researcher at the University of Tokyo, who will head the institute's programme on mantle-core dynamics.

Adam Dziewonski of Harvard University says that the new institute is well placed to become a "major hub" in subduction-zone research, thanks to its location and resources. The latter will include access to the Earth Simulator supercomputer at nearby Yokohama and to Japan's new ocean-drilling vessel, Chikyu (see Nature 415, 356; 2002), whose research programmes will be led by JAMSTEC.

The institute's success, researchers say, will hinge on its ability to foster multidisciplinary collaboration between its four programmes - in mantle-core dynamics, geochemical evolution, plate tectonics and palaeoenvironmental studies.

Such collaboration could be extremely beneficial, says Barbara Romanowicz, director of the Siesmological Laboratory at the University of California, Berkeley, who has proposed a similar institute there. "I would expect that IFREE will indeed lead to the kind of breakthroughs that our field needs," she says.

www.jamstec.go.jp/jamstec-j/IFREE 